\title{
Prone positioning in high-flow nasal cannula for COVID-19 patients with severe hypoxemia: a pilot study
}

\author{
Guo-Wei Tu ${ }^{1 \#}$, You-Xia Liao ${ }^{2 \#}$, Qing-Yun Li $^{3 \#}$, Hui Dong ${ }^{2}$, Lu-Yu Yang ${ }^{2}$, Xiao-Yun Zhang ${ }^{4}$, \\ Shou-Zhi Fu' ${ }^{2}$, Rui-Lan Wang ${ }^{5}$
}

${ }^{1}$ Department of Critical Care Medicine, Zhongshan Hospital, Fudan University, Shanghai 200032, China; ${ }^{2}$ Department of ICU/Emergency, Wuhan Third Hospital, Wuhan University, Wuhan 430074, China; ${ }^{3}$ Department of Respiratory and Critical Care Medicine, Ruijin Hospital, Shanghai Jiao Tong University School of Medicine, Shanghai 200025, China; ${ }^{4}$ Department of Nursing, Zhongshan Hospital, Fudan University, Shanghai 200032, China; ${ }^{5}$ Department of Critical Care Medicine, Shanghai General Hospital, Shanghai Jiao Tong University School of Medicine, Shanghai 201600, China

"These authors contributed equally to this work.

Correspondence to: Rui-Lan Wang. Department of Critical Care Medicine, Shanghai General Hospital, Shanghai Jiao Tong University School of Medicine, Songjiang, Shanghai 201600, China. Email: wangyusun@hotmail.com; Shou-Zhi Fu. Department of ICU/Emergency, Wuhan Third Hospital, Wuhan University, Wuhan 430074, China. Email: fszfsz188@163.com.

Submitted Mar 31, 2020. Accepted for publication Apr 29, 2020.

doi: $10.21037 / \mathrm{atm}-20-3005$

View this article at: http://dx.doi.org/10.21037/atm-20-3005

The COVID-19 outbreak has become a global pandemic within only a few months. COVID-19 patients complicated with severe hypoxemia usually required high-flow nasal cannula (HFNC) and mechanical ventilation. Prone positioning is a salvage therapy for refractory hypoxemia and has proven to be effective in increasing tidal volume and improving oxygenation and diaphragmatic function in patients with acute respiratory distress syndrome (ARDS) (1-3). However, all these studies were conducted in intubated patients. A recent study revealed that early application of prone positioning with the HFNC might avoid the need for intubation in moderate to severe ARDS patients (4), suggesting that the benefits of prone positioning also exists in the non-intubated patients (5). Also, endotracheal intubation may carry high nosocomial infection risk for the physicians who perform this procedure. Avoiding intubation could also be protective of them. Based on these potential beneficial effects, we conducted a pilot study and reviewed our preliminary experience of prone positioning in HFNC to treat COVID-19 who were complicated with severe hypoxemia.

Patients diagnosed with COVID-19 were enrolled if HFNC was delivered more than 2 days, and $\mathrm{PaO}_{2} / \mathrm{FiO}_{2}$ was less than $150 \mathrm{mmHg}$. The flow rate was initially set at 50
$60 \mathrm{~L} / \mathrm{min}$, and the fraction of inspired oxygen concentration $\left(\mathrm{FiO}_{2}\right)$ was titrated to maintain the $\mathrm{SpO}_{2}$ more than $90 \%$. Between 1 February and 10 March 2020, 9 patients were included in this pilot study, and informed consents were obtained from participants or their family members. The clinical characteristics of these 9 COVID-19 patients were summarized in Table 1.

Prone positioning was applied with a median of 5 (IQR: $3-8)$ procedures per subject (twice daily). The median duration was 2 (IQR: 1-4) hours. HFNC settings were kept constant before and during the prone positioning. Physicians and nurses monitored the respiratory and hemodynamic parameters closely. Patients who could not tolerate prone positioning were allowed to interrupt and back to the supine position. No sedation was used in this study for safety concerns. The arterial blood before and after prone positioning were collected at the first time (Figure 1). The mean blood oxygen saturation was increased from $90 \% \pm 2 \%$ to $96 \% \pm 3 \%(\mathrm{P}<0.001)$, and the mean blood oxygen partial pressure was increased from $69 \pm 10$ to 108 $\pm 14 \mathrm{mmHg}(\mathrm{P}<0.001)$. The mean partial pressure of carbon dioxide was decreased from $47 \pm 7$ to $39 \pm 5 \mathrm{mmHg}(\mathrm{P}=0.007)$. Two patients ultimately required invasive mechanical ventilation: One was successfully extubated after 8 days, and the other received venovenous extracorporeal membrane 
A

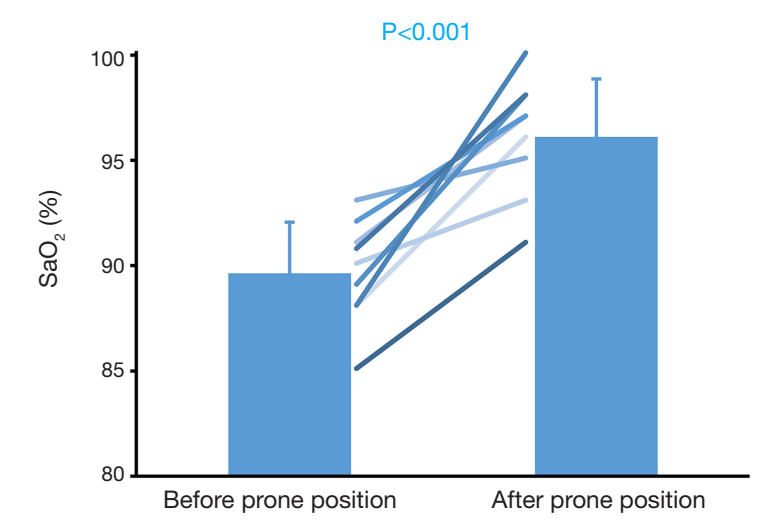

C

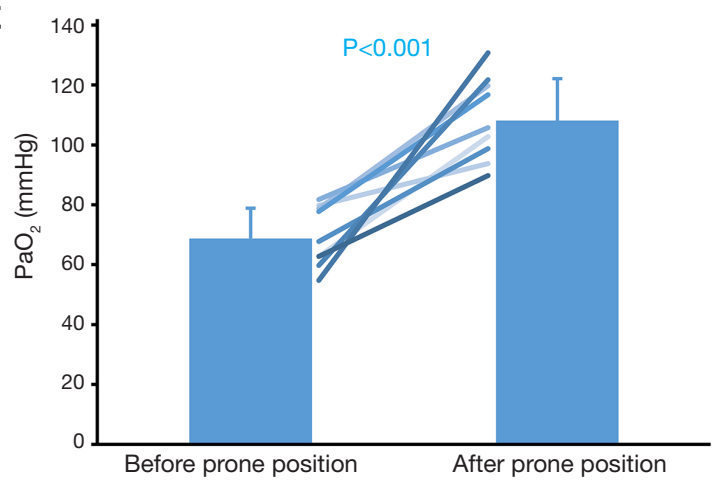

B

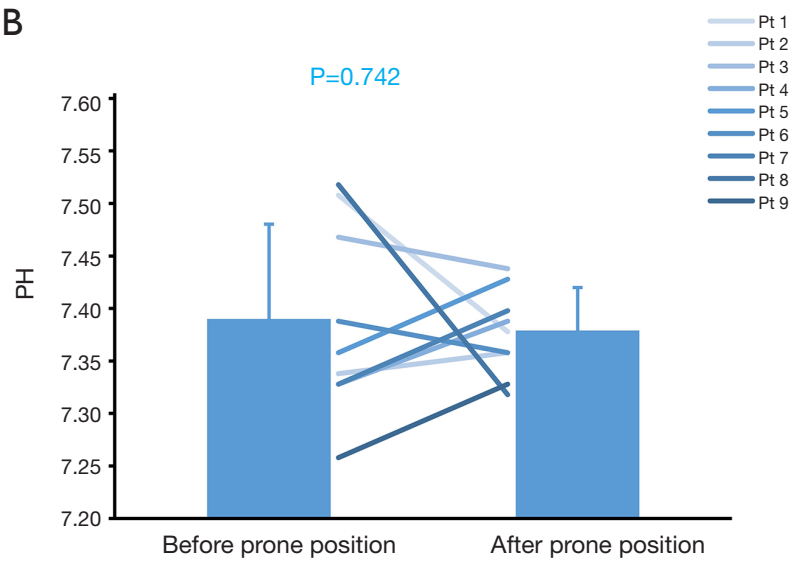

D

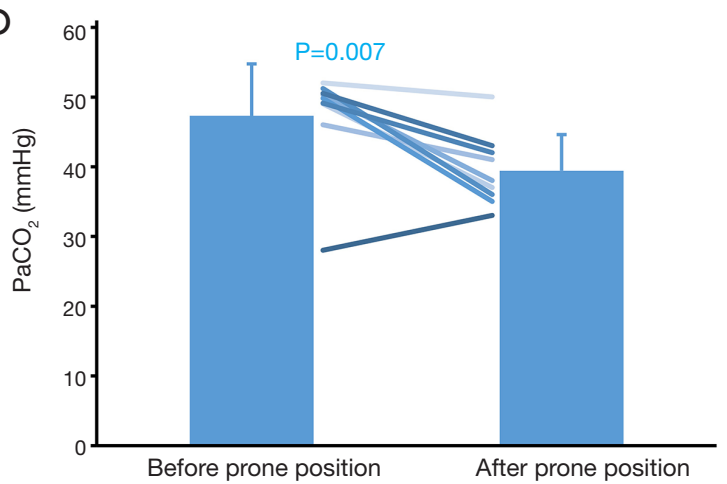

Figure 1 Comparison of $\mathrm{SaO}_{2}, \mathrm{PaO}_{2}, \mathrm{PaCO}_{2}$ and $\mathrm{PH}$ before and after prone positioning.

oxygenation.

This is the first study to evaluate the effect of prone positioning during HFNC in COVID-19 patients. Our study revealed that prone positioning was safe and associated with improved oxygenation in HFNC patients with severe hypoxemia. We did not observe any major adverse events, such as hemodynamic instability or aspiration.

Although the results are encouraging, they should be interpreted with great caution. Although prone positioning has been reported to have physiological effects of "lung recruitment", which could improve ventilation-perfusion matching, further investigation of the mechanism is still warranted in HFNC patients. In the current study, 7 out of 9 patients successfully avoided invasive mechanical ventilation, which indicated that prone positioning might help avoid intubation in HFNC patients. However, the small sample size of the study and lack of controlled group precluded the establishment of definitive conclusions.

Besides, the optimal timing of prone positioning initiation in severe hypoxemia patients with HFNC remains unknown. In the PROSEVA trial, Guérin et al. included ARDS patients with $\mathrm{PaO}_{2} / \mathrm{FiO}_{2}$ less than $150 \mathrm{mmHg}$ and $\mathrm{FiO}_{2}$ at least $60 \%$ (2). However, this enrollment criteria were based on intubated patients rather than HFNC. In this study, prone positioning was used as a "salvage therapy". It should be noted that if the invasive mechanical ventilation is inevitable and the situation is emergent, delayed intubation of patients will increase, rather than decrease, the mortality $(6,7)$. When combined with HFNC, whether prone positioning should be used as "preemptive strategy" or "salvage therapy" need to be further evaluated.

In conclusion, our pilot study revealed that prone positioning combined with HFNC could improve oxygenation and potentially avoided invasive mechanical ventilation. Further large-scale studies are needed to confirm our results.

\section{Acknowledgments}

We thank all the authors in the battle against COVID-19 
Table 1 Clinical characteristic of 9 HFNC patients with COVID-19

\begin{tabular}{|c|c|}
\hline Variables & Outcome \\
\hline Age (yrs) & $51 \pm 11$ \\
\hline Male sex, n (\%) & $4(44.44 \%)$ \\
\hline \multicolumn{2}{|l|}{ Symptoms on admission, n (\%) } \\
\hline Fever & $9(100 \%)$ \\
\hline Cough & $6(66.67 \%)$ \\
\hline Dyspnea & $2(22.22 \%)$ \\
\hline \multicolumn{2}{|l|}{ Comorbidities, n (\%) } \\
\hline Hypertension & $3(33.33 \%)$ \\
\hline Diabetes mellitus & $1(11.11 \%)$ \\
\hline WBC $\left(\times 10^{9} / L\right)$ & $5.08 \pm 1.64$ \\
\hline $\operatorname{ALC}\left(\times 10^{9} / \mathrm{L}\right)$ & $0.67 \pm 0.10$ \\
\hline Lymphocyte \% & $14.11 \pm 3.50$ \\
\hline Neutrophils \% & $80.47 \pm 4.97$ \\
\hline Creatinine ( $\mu \mathrm{mol} / \mathrm{L})$ & $68.93 \pm 17.22$ \\
\hline D-dimer (mg/L) & $0.90(0.41-2.57)$ \\
\hline BNP (pg/mL) & $52.53 \pm 61.22$ \\
\hline Troponin T ( $\mu \mathrm{g} / \mathrm{L})$ & $0.01(0.00-0.02)$ \\
\hline $\mathrm{FiO}_{2}(\%)$ & $80 \pm 5$ \\
\hline Flow rate (L/min) & 60 \\
\hline Intubation required, n (\%) & $2(22.22 \%)$ \\
\hline Duration of HFNC before PP (days) & $4 \pm 1$ \\
\hline Duration from disease onset to inclusion (days) & $11 \pm 3$ \\
\hline Length of stay in ICU (days) & $15 \pm 7$ \\
\hline Length of stay in hospital (days) & $28 \pm 10$ \\
\hline
\end{tabular}

Values are given as mean \pm standard deviation, median (25-75\% interquartile range), $\mathrm{n}(\%)$. HFNC, high-flow nasal cannula; WBC, white blood count; ALC, absolute lymphocyte count; BNP, probrain natriuretic peptide; $\mathrm{FiO}_{2}$, fraction of inspiration oxygen; $\mathrm{PP}$, prone positioning; ICU, intensive care unit. epidemic in Wuhan.

Funding: None.

\section{Footnote}

Peer Review File: Available at http://dx.doi.org/10.21037/ atm-20-3005

Conflicts of Interest: All authors have completed the ICMJE uniform disclosure form (available at http://dx.doi. org/10.21037/atm-20-3005). GWT serves as an unpaid Section Editor of Annals of Translational Medicine from Oct 2019 to Sep 2020. The other authors have no conflicts of interest to declare.

Ethical Statement: The authors are accountable for all aspects of the work in ensuring that questions related to the accuracy or integrity of any part of the work are appropriately investigated and resolved.

Open Access Statement: This is an Open Access article distributed in accordance with the Creative Commons Attribution-NonCommercial-NoDerivs 4.0 International License (CC BY-NC-ND 4.0), which permits the noncommercial replication and distribution of the article with the strict proviso that no changes or edits are made and the original work is properly cited (including links to both the formal publication through the relevant DOI and the license). See: https://creativecommons.org/licenses/by-nc-nd/4.0/.

\section{References}

1. Guérin C, Beuret P, Constantin JM, et al. A prospective international observational prevalence study on prone positioning of ARDS patients: the APRONET (ARDS Prone Position Network) study. Intensive Care Med 2018;44:22-37. 
2. Guérin C, Reignier J, Richard JC, et al. Prone positioning in severe acute respiratory distress syndrome. $\mathrm{N}$ Engl J Med 2013;368:2159-68.

3. Pugliese F, Babetto C, Alessandri F, et al. Prone Positioning for ARDS: still misunderstood and misused. J Thorac Dis 2018;10:S2079-82.

4. Ding L, Wang L, Ma W, et al. Efficacy and safety of early prone positioning combined with HFNC or NIV in moderate to severe ARDS: a multi-center prospective cohort study. Crit Care 2020;24:28.

5. Scaravilli V, Grasselli G, Castagna L, et al. Prone

Cite this article as: Tu GW, Liao YX, Li QY, Dong H, Yang LY, Zhang XY, Fu SZ, Wang RL. Prone positioning in high-flow nasal cannula for COVID-19 patients with severe hypoxemia: a pilot study. Ann Transl Med 2020;8(9):598. doi: 10.21037/atm-20-3005 positioning improves oxygenation in spontaneously breathing nonintubated patients with hypoxemic acute respiratory failure: A retrospective study. J Crit Care 2015;30:1390-4.

6. Carrillo A, Gonzalez-Diaz G, Ferrer M, et al. Noninvasive ventilation in community-acquired pneumonia and severe acute respiratory failure. Intensive Care Med 2012;38:458-66.

7. Grasselli G. ICU admission of patients with hematological malignancies: the debate continues. Minerva Anestesiol 2013;79:113-5. 